\title{
Elevation of circulating fatty acid-binding protein 4 is independently associated with left ventricular diastolic dysfunction in a general population
}

\author{
Takahiro Fuseya $^{1 \dagger}$, Masato Furuhashi ${ }^{1{ }^{*}}$, Satoshi Yuda ${ }^{1,2}$, Atsuko Muranaka ${ }^{1}$, Mina Kawamukai ${ }^{1}$, Tomohiro Mita ${ }^{1}$, \\ Shutaro Ishimura', Yuki Watanabe', Kyoko Hoshina', Marenao Tanaka', Kohei Ohno', Hiroshi Akasaka', \\ Hirofumi Ohnishi ${ }^{1,3}$, Hideaki Yoshida', Shigeyuki Saitoh ${ }^{1,4}$, Kazuaki Shimamoto ${ }^{5}$ and Tetsuji Miura ${ }^{1}$
}

\begin{abstract}
Background: Fatty acid-binding protein 4 (FABP4) is expressed in both adipocytes and macrophages. Recent studies have shown secretion of FABP4 from adipocytes and association of elevated serum FABP4 level with obesity, insulin resistance, hypertension, and atherosclerosis. However, little is known about role of FABP4 in cardiac function.

Methods: From the database of the Tanno-Sobetsu Study, data for 190 subjects (male/female: 82/108) who were not treated with any medication and underwent echocardiography in 2011 or 2012 were retrieved for analyses of relationships between serum FABP4 concentration, metabolic markers and parameters of echocardiography.

Results: Serum FABP4 level was positively correlated with age, body mass index (BMI), blood pressure (BP), LDL cholesterol, HOMA-R and mean left ventricular (LV) wall thickness (LVWT, males: $r=0.315$, females: $r=0.401$, $p<0.01)$ and was negatively correlated with $\mathrm{HDL}$ cholesterol, estimated glomerular filtration rate $(\mathrm{eGFR})$ and peak myocardial velocity during early diastole (e'; males: $r=-0.434$, females: $r=-0.353, p<0.01$ ), an index of LV diastolic function. However, no significant correlation was found between FABP4 level and LV end-diastolic dimension, LV ejection fraction or LV mass index. There were significant correlations of $e^{\prime}$ with age, BMI, BP, eGFR, brain natriuretic peptide (BNP), FABP4, metabolic markers and LVWT. Multivariate regression analysis adjusted by HOMA-R, BMI, eGFR, BNP or LVWT in addition to age, gender and BP revealed that serum FABP4 concentration was independently correlated with $e^{\prime}$.
\end{abstract}

Conclusions: Elevation of circulating FABP4 may contribute to LV diastolic dysfunction in a general population.

Keywords: Fatty acid-binding protein 4, Adipokine, Left ventricular diastolic dysfunction

\section{Background}

Fatty acid-binding proteins (FABPs) are a group of intracellular lipid chaperones that coordinate lipid responses in cells $[1,2]$. FABPs are about $14-15-\mathrm{kDa}$ proteins that can reversibly bind hydrophobic ligands, such as saturated and unsaturated long chain fatty acids, with high affinity $[1,2]$. FABPs have been proposed to facilitate the transport of lipids to specific compartments in the cell. Among FABPs, fatty acid-binding protein 4 (FABP4), known as

\footnotetext{
* Correspondence: furuhasi@sapmed.ac.jp

${ }^{\dagger}$ Equal contributors

'Department of Cardiovascular, Renal and Metabolic Medicine, Sapporo Medical University School of Medicine, S-1, W-16 Chuo-ku, Sapporo 060-8543, Japan

Full list of author information is available at the end of the article
}

adipocyte FABP (A-FABP) or aP2, is expressed in adipocytes, macrophages and capillary endothelial cells [1-3]. Emerging evidence indicates that FABP4 acts at the integration between metabolic and inflammatory pathways and plays an important role in the development of insulin resistance and atherosclerosis [4-6]. It has also been demonstrated in experimental models that chemical inhibition of FABP4 could be a therapeutic strategy against insulin resistance, diabetes mellitus, fatty liver disease and atherosclerosis [7].

Adipose tissue is now known to secrete a variety of bioactive molecules called adipokines, such as tumor necrosis factor- $\alpha$ (TNF $\alpha)$, leptin and adiponectin, which are implicated in a wide range of biological phenomena. 
Interestingly, recent studies have shown that FABP4 is secreted from adipocytes $[8,9]$, though there are no typical signal peptides for secretion in the sequence of FABP4 [1]. It has also been demonstrated that secretion of FABP4 is via a non-classical secretion pathway and that FABP4 acts as an adipokine for the development of hepatic insulin resistance [9]. Furthermore, elevated serum concentration of FABP4 has been shown to be associated with obesity, insulin resistance, hypertension and atherosclerosis [8-12].

Obesity is a risk factor for several kinds of cardiac insults, such as left ventricular (LV) hypertrophy, LV diastolic dysfunction and heart failure with preserved or reduced ejection fraction. It has been suggested that several adipokines provide a direct pathophysiological link between enlarged adipose tissue and obesity-associated cardiac dysfunction [13]. However, little is known about the relationship between circulating FABP4 and cardiac function, especially in a general population. Therefore, we hypothesized that increase in serum FABP4 reflects LV diastolic dysfunction as an early stage of cardiac insults in a general population. To address this hypothesis, we conducted a study to investigate the cross-sectional associations between serum FABP4 concentration and several echocardiographic parameters in subjects who had not regularly taken any medications.

\section{Methods}

\section{Study population}

The Tanno-Sobetsu Study is a study with a populationbased cohort design recruiting residents of two rural towns, Tanno and Sobetsu, in Hokkaido and includes annual health examination, pathophysiological assessment of metabolic syndrome and cardiovascular disease, and follow-up survey. A total of 357 female subjects (mean age: $66 \pm 13$ years) in 2011 and 277 male subjects (mean age: $66 \pm 13$ years) in 2012 received annual examinations in Sobetsu Town. Female and male participants in 2011 and 2012, respectively, were invited to receive echocardiographic examinations. Subjects who were being treated with any regular medications for diseases were excluded. Other exclusion criteria were atrial fibrillation and conductional abnormalities such as left bundle branch block on electrocardiogram or severe valvular disease and left ventricular hypertrophy (wall thickness $>12.5 \mathrm{~mm}$ ) on echocardiogram. A total of 190 subjects who underwent echocardiography (male/female: $82 / 108$, mean age: $63 \pm 13$ years) contributed to the present analyses. This study conformed to the principles outlined in the Declaration of Helsinki and was performed with the approval of the Ethical Committee of Sapporo Medical University. Written informed consent was received from all of the subjects.

\section{Measurements}

Medical check-ups were performed between 06:00 h and 09:00 h after an overnight fast. After measuring anthropometric parameters, blood pressure was measured twice consecutively on the upper arm using an automated sphygmomanometer (HEM-907, Omron Co., Kyoto, Japan) with subjects in a seated resting position, and average blood pressure was used for analysis. Body mass index (BMI) was calculated as body weight (in kilograms) divided by the square of body height (in meters). Peripheral venous blood samples were obtained from study subjects after physical examination for complete blood count and biochemical analyses of the serum. The serum samples were analyzed immediately or stored at $-80^{\circ} \mathrm{C}$ until biochemical analyses.

Serum concentration of FABP4 was measured using a commercially available enzyme-linked immunosorbent assay kit for FABP4 (Biovendor R\&D, Modrice, Czech Republic). The accuracy, precision and reproducibility of the kit have been described previously [8]. The intra- and inter-assay coefficient variances in the kit were $<5 \%$. Fasting plasma glucose was determined by the glucose oxidase method. Fasting plasma insulin was measured by a radioimmunoassay method (Insulin RIA bead, Dianabot, Tokyo, Japan). Creatinine ( $\mathrm{Cr}$ ) and lipid profiles, including total cholesterol, high-density lipoprotein (HDL) cholesterol and triglycerides, were determined by enzymatic methods. Low-density lipoprotein (LDL) cholesterol level was calculated by the Friedewald equation. Hemoglobin A1c (HbA1c) was determined by a latex coagulation method and was expressed in national glycohemoglobin standardization program (NGSP) scale. Brain natriuretic peptide (BNP) was measured using an assay kit (Shionogi \& Co., Osaka, Japan). High-sensitivity C-reactive protein (hsCRP) was measured by a nephelometry method. As an index of renal function, estimated glomerular filtration rate (eGFR) was calculated by an equation for Japanese: $\mathrm{eGFR}\left(\mathrm{ml} / \mathrm{min} / 1.73 \mathrm{~m}^{2}\right)=194 \times \mathrm{Cr}^{(-1.094)} \times \operatorname{age}^{(-0.287)} \times 0.739$ (if female). HOMA-R, an indicator of insulin resistance, was calculated by the previously reported formula: in$\operatorname{sulin}(\mu \mathrm{U} / \mathrm{ml}) \times \operatorname{glucose}(\mathrm{mg} / \mathrm{dl}) / 405$.

\section{Echocardiography}

After medical check-ups and collection of urine and blood samples, echocardiographic examinations were performed by three well-experienced echocardiographers who were blinded to clinical data, using Vivid 9 (GE Health Care, Tokyo, Japan) equipped with a $2.5-\mathrm{MHz}$ frequency transducer. Two-dimensional and color tissue Doppler imaging modes were used to obtain images from standard echocardiographic views, including parasternal long-axis and apical four-, three-, and two chamber views at a left lateral decubitus position. Standard parameters in two-dimensional measurements, including LV end-diastolic 
and end-systolic dimensions ( $\mathrm{mm}$ ) and septal and posterior wall thicknesses at end-diastole $(\mathrm{mm})$, were determined. Mean LV wall thickness $(\mathrm{mm})$ was calculated by the average of septal and posterior wall thicknesses at end-diastole. LV ejection fraction (\%) was calculated using biplane modified Simpson's method. LV mass was calculated according to the recommendations of the American Society of Echocardiography [14] and normalized for body surface area (LV mass index, $\mathrm{g} / \mathrm{m}^{2}$ ). Left atrial (LA) dimension $(\mathrm{mm})$ was measured by M-mode echocardiography, and LA volume was measured using biplane Simpson's method and normalized for body surface area (LA volume index, $\mathrm{ml} / \mathrm{m}^{2}$ ) [14]. Each parameter was evaluated by averaging two to three measurements. Transmitral flow velocities were obtained by pulsed wave Doppler echocardiography, positioning a sample volume at the level of a mitral tip in an apical four-chamber view. Mitral flow parameters, including peak velocities during early (E) and late diastole (A) and $\mathrm{E}$-wave deceleration time, were measured, and the E/A ratio was calculated. Tissue velocity curves were obtained from color tissue Doppler imaging. A sample volume was placed at the lateral annulus in the apical four-chamber view, and peak myocardial velocity during early diastole $\left(\mathrm{e}^{\prime}, \mathrm{cm} / \mathrm{sec}\right)$ was measured, and the ratio of mitral to myocardial early diastolic peak velocity $\left(E / e^{\prime}\right)$ was calculated.

\section{Statistical analysis}

Numeric variables are expressed as means \pm SD for normal distributions or medians (interquartile ranges) for skewed variables. The distribution of each parameter was tested for its normality using the Shapiro-Wilk W test, and non-normally distributed parameters were logarithmically transformed for comparison and regression analyses. Comparison between two groups was done with an unpaired $t$ test. One-way analysis of variance and Tukey-Kramer post hoc test were used for detecting significant differences in data between multiple groups. The correlation between two variables was evaluated using Pearson's correlation coefficient. Multivariate regression analysis was performed to identify independent determinants of e' using the variables with a significant and nonconfounding correlation in simple regression analysis as independent predictors, showing the $\mathrm{t}$-ratio calculated as the ratio of regression coefficient and standard error of regression coefficient and the percentage of variance in the object variables that they explained $\left(R^{2}\right)$. A p value of less than 0.05 was considered statistically significant. HolmBonferroni sequential correction was also performed in multivariate regression analysis. All data were analyzed by using JMP 9 for Macintosh (SAS Institute, Cary, NC).

\section{Results}

Basal characteristics of the study subjects are shown in Table 1. Male subjects were significantly older than the female subjects and they had significantly larger BMI and waist circumference and had higher levels of systolic and diastolic blood pressures, triglycerides, glucose, HbA1c, insulin, HOMA-R and $\mathrm{Cr}$ and lower levels of total cholesterol, HDL cholesterol, LDL cholesterol and FABP4 than did the females. No significant difference in eGFR or BNP was found between male and female subjects. In echocardiographic parameters, LA dimension, mean LV wall thickness, LV end-diastolic dimension, LV mass index and E-wave deceleration time were significantly larger in males than in females. On the other hand, LV ejection fraction and E/A ratio were smaller in males than in females. Levels of e' and E/e' were comparable between male and female subjects.

In analyses of data from all study subjects, serum FABP4 level was positively correlated with age, BMI, systolic and diastolic blood pressures, total cholesterol, LDL cholesterol, triglycerides, insulin, HOMA-R, $\mathrm{Cr}$ and hsCRP and was negatively correlated with eGFR (Table 2). Similar correlations between the parameters were observed when male and female subjects were separately analyzed.

Regarding echocardiographic parameters, FABP4 concentration was positively correlated with LA dimension, LA volume index and mean LV wall thickness (males: $r=0.315$, females: $r=0.401, p<0.01$ ), though correlation with FABP4 was not significant for LV end-diastolic dimension or LV mass index. FABP4 level was positively correlated with E/e' and negatively correlated with e' (Figure 1; males: $r=-0.434$, females: $r=-0.353, p<0.001)$, an index of LV diastolic function, and E/A ratio (Table 2), whereas LV ejection fraction was not correlated with FABP4 level. Among echocardiographic parameters, e' was positively correlated with LV ejection fraction and E/A ratio and was negatively correlated with LA dimension, LA volume index, mean LV wall thickness, LV mass index, E-wave deceleration time and E/e' (Table 3). Of extra-cardiac parameters, age, BMI, waist circumference, systolic and diastolic blood pressures and biochemical markers, including eGFR, BNP, hsCRP and FABP4, were found to be significantly correlated with e' (Table 3).

Multivariate regression analysis was performed to identify independent determinants of e' using systolic blood pressure, the most strongly correlated factor among anthropometric and biochemical parameters $(r=-0.465$, $\mathrm{p}<0.001$ ), in addition to age and gender (Model 1) and showed that serum FABP4 concentration was independently correlated with e' (Table 4). Next, the variables with a significant and non-confounding correlation in simple regression analysis were additionally chosen as possible independent predictors in Model $2 \sim 6$ : a marker of adiposity (BMI, Model 2), glucose and insulin metabolism (HOMA-R, Model 3), renal function (eGFR, Model 4), cardiac damage (BNP, Model 5) or cardiac morphology (LV wall thickness, Model 6). When the each parameter 
Table 1 Characteristics of the studied subjects

\begin{tabular}{|c|c|c|c|}
\hline & Whole & Male & Female \\
\hline $\mathrm{n}$ & 190 & 82 & 108 \\
\hline Age (years) & $63 \pm 13$ & $66 \pm 13$ & $60 \pm 13^{*}$ \\
\hline Body mass index $\left(\mathrm{kg} / \mathrm{m}^{2}\right)$ & $23.2 \pm 3.7$ & $24.4 \pm 3.9$ & $22.3 \pm 3.4^{*}$ \\
\hline Waist circumference $(\mathrm{cm})$ & $84 \pm 11$ & $88 \pm 11$ & $81 \pm 10^{*}$ \\
\hline Systolic blood pressure (mmHg) & $134 \pm 21$ & $138 \pm 18$ & $130 \pm 22^{*}$ \\
\hline Diastolic blood pressure $(\mathrm{mmHg})$ & $77 \pm 11$ & $79 \pm 10$ & $75 \pm 12 \dagger$ \\
\hline \multicolumn{4}{|l|}{ Biochemical data } \\
\hline Total cholesterol (mg/dl) & $202 \pm 33$ & $188 \pm 29$ & $212 \pm 32^{*}$ \\
\hline HDL cholesterol (mg/dl) & $68 \pm 18$ & $59 \pm 17$ & $75 \pm 16^{*}$ \\
\hline LDL cholesterol (mg/dl) & $119 \pm 29$ & $108 \pm 28$ & $127 \pm 28^{*}$ \\
\hline Triglycerides (mg/dl) & $83(64-112)$ & $93(70-132)$ & $77(57-100)^{*}$ \\
\hline Glucose (mg/dl) & $92(87-99)$ & $97(91-103)$ & $90(85-96)^{*}$ \\
\hline $\mathrm{HbA1c}(\%)$ & $5.5 \pm 0.5$ & $5.6 \pm 0.5$ & $5.4 \pm 0.4^{*}$ \\
\hline Insulin $(\mu \mathrm{U} / \mathrm{ml})$ & $4.5(3.4-6.9)$ & $4.9(3.6-7.6)$ & $4.2(3.2-6.1)^{*}$ \\
\hline HOMA-R & $1.02(0.74-1.63)$ & $1.21(0.85-1.92)$ & $0.94(0.68-1.37)^{*}$ \\
\hline Creatinine (mg/dl) & $0.74 \pm 0.17$ & $0.87 \pm 0.16$ & $0.65 \pm 0.11^{*}$ \\
\hline eGFR $\left(\mathrm{ml} / \mathrm{min} / 1.73 \mathrm{~m}^{2}\right)$ & $72 \pm 14$ & $71 \pm 15$ & $74 \pm 14$ \\
\hline BNP (pg/ml) & $28(11-31)$ & $14(9-33)$ & $21(12-31)$ \\
\hline $\mathrm{hsCRP}(\mathrm{mg} / \mathrm{dl})$ & $0.03(0.02-0.07)$ & $0.04(0.02-0.08)$ & $0.03(0.02-0.06)$ \\
\hline FABP4 (ng/ml) & $12.2(8.4-16.2)$ & $10.9(8.1-14.2)$ & $13.3(9.1-17.0) \dagger$ \\
\hline \multicolumn{4}{|l|}{ Echocardiographic parameters } \\
\hline Left atrial dimension (mm) & $34 \pm 6$ & $36 \pm 6$ & $33 \pm 6^{*}$ \\
\hline Left atrial volume index $\left(\mathrm{ml} / \mathrm{m}^{2}\right)$ & $27 \pm 8$ & $26 \pm 8$ & $27 \pm 8$ \\
\hline Mean LV wall thickness (mm) & $8.8 \pm 1.2$ & $9.6 \pm 0.9$ & $8.2 \pm 0.9^{*}$ \\
\hline LV end-diastolic dimension (mm) & $44 \pm 5$ & $45 \pm 5$ & $43 \pm 4^{*}$ \\
\hline LV mass index $\left(\mathrm{g} / \mathrm{m}^{2}\right)$ & $93 \pm 23$ & $102 \pm 22$ & $86 \pm 21^{*}$ \\
\hline LV ejection fraction (\%) & $67 \pm 5$ & $66 \pm 6$ & $67 \pm 5+$ \\
\hline$E / A$ & $0.91(0.75-1.19)$ & $0.79(0.68-0.94)$ & $0.98(0.79-1.31)^{*}$ \\
\hline E-wave deceleration time (msec) & $214 \pm 53$ & $223 \pm 59$ & $207 \pm 47 \dagger$ \\
\hline $\mathrm{e}^{\prime}(\mathrm{cm} / \mathrm{sec})$ & $10.2 \pm 3.1$ & $9.7 \pm 3.2$ & $10.6 \pm 3.0$ \\
\hline$E / e^{\prime}$ & $7.0 \pm 2.3$ & $6.7 \pm 2.3$ & $7.3 \pm 2.3$ \\
\hline
\end{tabular}

Variables are expressed as number, means \pm SD or medians (interquartile ranges). BNP, brain natriuretic peptide; eGFR, estimated glomerular filtration rate; hsCRP, high-sensitivity $C$-reactive protein; $L V$, left ventricle. ${ }^{*} P<0.01,+P<0.05$ vs. male.

was additionally incorporated into the adjustment, FABP4 remained as an independent predictor of $\mathrm{e}^{\prime}$ in Model $2 \sim 6$ (Table 4), although the independent correlation in Model 2 was cancelled after Holm-Bonferroni sequential correction. Additional multivariate regression analysis using all of the used parameters in Model $1 \sim 6$, including age, gender, systolic blood pressure, BMI, HOMA-R, eGFR, BNP, mean LV wall thickness and FABP4, showed that FABP4 level $(t=-2.36, p=0.020)$ was independently correlated with e' after adjustment of other variables (overall $\mathrm{R}^{2}=0.563$ ).

In low and middle tertiles of BMI, e' in a group with low levels of FABP4 (FABP4-Low) was significantly higher than that in a group with high levels of FABP4 (FABP4High) (Figure 2). Furthermore, there was no significant difference in e' between the FABP4-Low and FABP4-High groups in high tertile of BMI, but the FABP4-Low group in high tertile of BMI had significantly lower e' than did that in low tertile of BMI.

\section{Discussion}

The salient finding in the present study was that FABP4 was independently and negatively correlated with e', which reflects LV relaxation and is known as one of the most sensitive indexes of LV diastolic function in a healthy population [14]. LV diastolic dysfunction often precedes 
Table 2 Simple regression analysis for log FABP4

\begin{tabular}{|c|c|c|c|c|c|c|}
\hline & \multicolumn{2}{|c|}{ Whole $(n=190)$} & \multicolumn{2}{|c|}{ Male $(n=82)$} & \multicolumn{2}{|c|}{ Female $(n=108)$} \\
\hline & $r$ & $p$ & $r$ & $p$ & $r$ & $p$ \\
\hline Age & 0.225 & 0.002 & 0.193 & 0.083 & 0.314 & 0.001 \\
\hline Body mass index & 0.500 & $<0.001$ & 0.580 & $<0.001$ & 0.564 & $<0.001$ \\
\hline Waist circumference & 0.518 & $<0.001$ & 0.642 & $<0.001$ & 0.518 & $<0.001$ \\
\hline Systolic blood pressure & 0.272 & $<0.001$ & 0.283 & 0.010 & 0.329 & 0.001 \\
\hline Diastolic blood pressure & 0.268 & $<0.001$ & 0.255 & 0.021 & 0.329 & 0.001 \\
\hline \multicolumn{7}{|l|}{ Biochemical data } \\
\hline Total cholesterol & 0.213 & 0.003 & 0.008 & 0.943 & 0.282 & 0.003 \\
\hline LDL cholesterol & 0.268 & $<0.001$ & 0.058 & 0.606 & 0.365 & $<0.001$ \\
\hline HDL cholesterol & -0.107 & 0.143 & -0.125 & 0.263 & -0.238 & 0.013 \\
\hline log Triglycerides & 0.157 & 0.031 & 0.097 & 0.385 & 0.282 & 0.003 \\
\hline log Glucose & 0.137 & 0.060 & 0.081 & 0.467 & 0.277 & 0.004 \\
\hline $\mathrm{HbA1c}$ & 0.046 & 0.532 & 0.044 & 0.695 & 0.107 & 0.272 \\
\hline log Insulin & 0.388 & $<0.001$ & 0.380 & 0.001 & 0.480 & $<0.001$ \\
\hline $\log$ HOMA-R & 0.386 & $<0.001$ & 0.384 & $<0.001$ & 0.489 & $<0.001$ \\
\hline Creatinine & 0.192 & 0.008 & 0.448 & $<0.001$ & 0.305 & 0.001 \\
\hline eGFR & -0.350 & $<0.001$ & -0.397 & $<0.001$ & -0.350 & $<0.001$ \\
\hline $\log B N P$ & 0.126 & 0.085 & 0.076 & 0.500 & 0.156 & 0.108 \\
\hline $\log$ hsCRP & 0.233 & 0.001 & 0.312 & 0.005 & 0.218 & 0.024 \\
\hline \multicolumn{7}{|l|}{ Echocardiographic parameters } \\
\hline Left atrial dimension & 0.251 & 0.001 & 0.354 & 0.001 & 0.290 & 0.002 \\
\hline Left atrial volume index & 0.231 & 0.002 & 0.226 & 0.050 & 0.225 & 0.020 \\
\hline Mean LV wall thickness & 0.195 & 0.007 & 0.315 & 0.004 & 0.401 & $<0.001$ \\
\hline LV end-diastolic dimension & -0.042 & 0.562 & 0.069 & 0.541 & -0.082 & 0.399 \\
\hline LV mass index & 0.039 & 0.596 & 0.085 & 0.448 & 0.105 & 0.281 \\
\hline LV ejection fraction & 0.113 & 0.121 & 0.219 & 0.048 & -0.023 & 0.812 \\
\hline $\log E / A$ & -0.178 & 0.016 & -0.173 & 0.131 & -0.279 & 0.004 \\
\hline E-wave deceleration time & 0.006 & 0.934 & -0.013 & 0.906 & 0.066 & 0.497 \\
\hline$e^{\prime}$ & -0.360 & $<0.001$ & -0.434 & $<0.001$ & -0.353 & $<0.001$ \\
\hline$E / e^{\prime}$ & 0.353 & $<0.001$ & 0.361 & 0.001 & 0.327 & 0.001 \\
\hline
\end{tabular}

BNP, brain natriuretic peptide; eGFR, estimated glomerular filtration rate; hSCRP, high-sensitivity C-reactive protein; LV, left ventricle.

LV systolic dysfunction in heart diseases, and moderate diastolic dysfunction alone potentially induces heart failure, which is referred to as heart failure with preserved ejection fraction (HFpEF) [15]. A recent study in which data from the Framingham cohort study were analyzed showed that age, diabetes mellitus, BMI, smoking and atrial fibrillation were predictors of HFpEF [16]. It is notable that the correlation of FABP4 level with e' was independent of age, BMI, HOMA-R and LV wall thickness (Table 4). These results suggest that serum FABP4 is a novel marker of LV diastolic dysfunction and potentially a predictor of HFpEF.

Previous studies using animal models indicated that FABP4 plays a significant role in several aspects of metabolic syndrome, including insulin resistance, type 2 diabetes and atherosclerosis, through its action at the interface of metabolic and inflammatory pathways in adipocytes and macrophages [1,2,4-6]. Epicardial fat has been reported to directly influence cardiac function because of the absence of a fibrous fascial layer between fat and the underlying myocardium $[17,18]$. FABP4 mRNA expression in epicardial adipose tissue was recently reported to be profoundly increased compared with its expression in paraaortic adipose tissue in patients with metabolic syndrome [19]. Furthermore, it has recently been reported that exogenous FABP4 acutely suppresses shortening amplitude in cardiomyocytes by attenuating intracellular systolic peak $\mathrm{Ca}^{2+}$ level in a dose-dependent manner [20] and impairs the insulin-dependent nitric oxide pathway in vascular endothelial cells [21]. Therefore, it is possible that either FABP4 


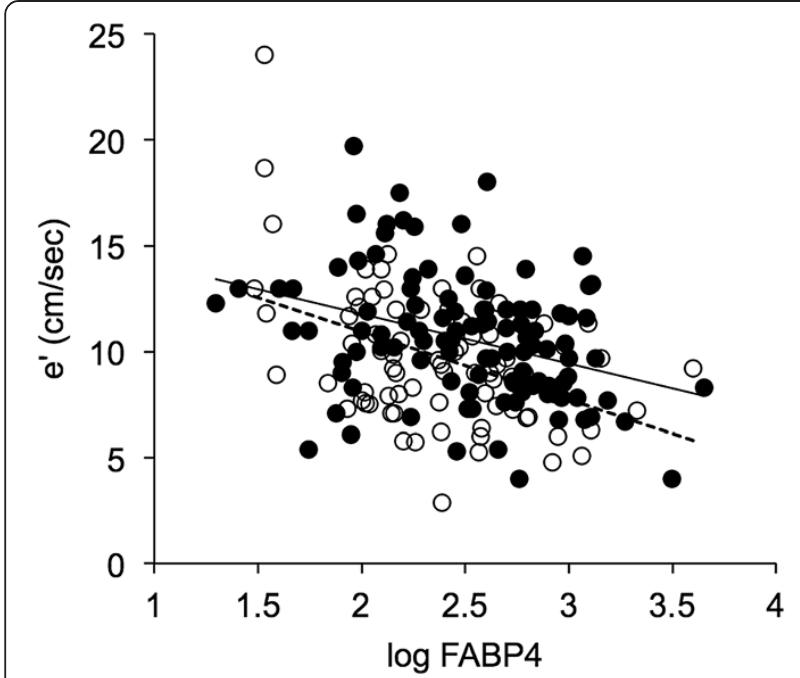

Figure 1 Association of serum FABP4 level with LV diastolic dysfunction. Peak myocardial velocity during early diastole (e'), an index of LV diastolic function, was plotted against log FABP4 for each subject. There was a significant correlation between the two parameters (males: $r=-0.434$, females: $r=-0.353, p<0.001$ ). Open circles: males $(n=82)$, closed circles: females $(n=108)$. Solid regression line: males, broken regression line: females.

secreted from epicardial fat tissue or circulating FABP4 released from subcutaneous and/or visceral adipose tissue or from macrophages may directly modulate cardiac function. In the heart, FABP3 known as heart-type FABP (H-FABP) is abundant and is rapidly released from cells into the circulation after onset of cardiomyocyte damage. Serum concentration of FABP3 has been characterized as an early biochemical marker of acute myocardial infarction and a sensitive marker of ongoing myocardial damage in patients with heart failure [22,23]. Impact of circulating FABP3 is apparently different from that of FABP4.

Inflammation is an important factor in the pathogenesis and progression of heart failure. It has been shown that increased inflammatory cytokines produced by mononuclear cells including macrophages and/or damaged myocardium impaired myocardial function by inducing apoptosis, necrosis and hypertrophic response in cardiomyocytes [24]. In the Framingham Heart Study, increased inflammatory markers, such as CRP, interleukin-6 and TNF $\alpha$ levels, were able to identify asymptomatic older subjects in the community who were at high risk for the future development of heart failure [25]. In the present study, FABP4 was positively correlated with hsCRP, being consistent with the results of several previous studies $[10,12]$. The macrophage is a critical site of FABP4 action, and macrophage-specific FABP4 deficiency leads to reduced activation of nuclear factor $\kappa \mathrm{B}(\mathrm{NF}-\mathrm{kB})$ and c-Jun Nterminal kinase (JNK), resulting in reduced production of a cluster of inflammatory cytokines [5]. Conversely, several inflammatory stimuli have been shown to cause
Table 3 Simple regression analysis for LV diastolic function

\begin{tabular}{|c|c|c|}
\hline & \multicolumn{2}{|l|}{$\mathrm{e}^{\prime}$} \\
\hline & $\mathbf{t}$ & $\mathbf{p}$ \\
\hline Age & -0.713 & $<0.001$ \\
\hline Body mass index & -0.200 & 0.006 \\
\hline Waist circumference & -0.324 & $<0.001$ \\
\hline Systolic blood pressure & -0.465 & $<0.001$ \\
\hline Diastolic blood pressure & -0.233 & 0.001 \\
\hline \multicolumn{3}{|l|}{ Biochemical data } \\
\hline Total cholesterol & -0.071 & 0.334 \\
\hline LDL cholesterol & -0.140 & 0.054 \\
\hline HDL cholesterol & 0.175 & 0.016 \\
\hline log Triglycerides & -0.148 & 0.042 \\
\hline log Glucose & -0.195 & 0.007 \\
\hline $\mathrm{HbA1c}$ & -0.210 & 0.004 \\
\hline log Insulin & -0.156 & 0.032 \\
\hline $\log$ HOMA-R & -0.187 & 0.010 \\
\hline Creatinine & -0.231 & 0.001 \\
\hline eGFR & 0.376 & $<0.001$ \\
\hline $\log B N P$ & -0.394 & $<0.001$ \\
\hline $\log$ hsCRP & -0.201 & 0.006 \\
\hline $\log$ FABP4 & -0.360 & $<0.001$ \\
\hline \multicolumn{3}{|l|}{ Echocardiographic parameters } \\
\hline Left atrial dimension & -0.289 & $<0.001$ \\
\hline Left atrial volume index & -0.233 & 0.002 \\
\hline Mean LV wall thickness & -0.370 & $<0.001$ \\
\hline LV end-diastolic dimension & 0.024 & 0.739 \\
\hline LV mass index & -0.294 & $<0.001$ \\
\hline LV ejection fraction & 0.148 & 0.043 \\
\hline $\log E / A$ & 0.644 & $<0.001$ \\
\hline E-wave deceleration time & -0.205 & 0.005 \\
\hline$E / e^{\prime}$ & -0.580 & $<0.001$ \\
\hline
\end{tabular}

$\mathrm{BNP}$, brain natriuretic peptide; eGFR, estimated glomerular filtration rate; hsCRP, high-sensitivity C-reactive protein; LV, left ventricle.

significantly increased expression of FABP4 in macrophages [5]. Local inflammation mediated by FABP4 in macrophages of the heart may participate in mediating cardiac dysfunction.

Up-regulation of FABP4 expression and other adipokines in heart failure has been demonstrated in recent studies [26-28], indicating complex neurohormonal and metabolic abnormalities associated with heart failure. Of note, upregulation of inflammatory cytokines, catecholamines and natriuretic peptides in heart failure is known to mediate increased lipolysis and insulin resistance [29]. It has been reported that lipolysis is mediated in part through the interaction of FABP4 with hormone-sensitive lipase in adipocytes [30]. A recent study also showed that FABP4 is 
Table 4 Multivariate regression analysis for LV diastolic function

\begin{tabular}{|c|c|c|c|c|c|}
\hline \multirow[b]{2}{*}{ Model } & \multicolumn{2}{|l|}{$\mathrm{e}^{\prime}$} & \multirow[b]{2}{*}{ Model } & \multicolumn{2}{|l|}{$\mathrm{e}^{\prime}$} \\
\hline & $\mathrm{t}$ & $p$ & & $\mathrm{t}$ & $\mathrm{p}$ \\
\hline Model 1 & & & Model 4 & & \\
\hline Age & -10.64 & $<0.001$ & Age & -10.27 & $<0.001$ \\
\hline Gender (Male) & -0.31 & 0.755 & Gender (Male) & -0.39 & 0.695 \\
\hline Systolic blood pressure & -1.83 & 0.069 & Systolic blood pressure & -1.88 & 0.062 \\
\hline \multirow[t]{3}{*}{$\log$ FABP4 } & -3.69 & $<0.001$ & eGFR & -1.34 & 0.181 \\
\hline & $R^{2}=0.558$ & & $\log$ FABP4 & -3.93 & $<0.001$ \\
\hline & & & & $R^{2}=0.562$ & \\
\hline Model 2 & & & Model 5 & & \\
\hline Age & -10.64 & $<0.001$ & Age & -9.11 & $<0.001$ \\
\hline Gender (Male) & 0.27 & 0.788 & Gender (Male) & -0.33 & 0.744 \\
\hline Systolic blood pressure & -1.57 & 0.118 & Systolic blood pressure & -1.80 & 0.073 \\
\hline Body mass index & -1.28 & 0.203 & $\log B N P$ & -0.33 & 0.742 \\
\hline \multirow[t]{2}{*}{$\log$ FABP4 } & -2.29 & 0.023 & $\log$ FABP4 & -3.70 & $<0.001$ \\
\hline & $R^{2}=0.562$ & & & $R^{2}=0.556$ & \\
\hline Model 3 & & & Model 6 & & \\
\hline Age & -10.45 & $<0.001$ & Age & -10.34 & $<0.001$ \\
\hline Gender (Male) & 0.09 & 0.925 & Gender (Male) & 0.17 & 0.866 \\
\hline Systolic blood pressure & -1.74 & 0.083 & Systolic blood pressure & -1.62 & 0.107 \\
\hline log HOMA-R & -0.89 & 0.376 & Mean LV wall thickness & -0.67 & 0.503 \\
\hline \multirow[t]{2}{*}{$\log$ FABP4 } & -3.01 & 0.003 & $\log$ FABP4 & -3.40 & $<0.001$ \\
\hline & $R^{2}=0.560$ & & & $R^{2}=0.559$ & \\
\hline
\end{tabular}

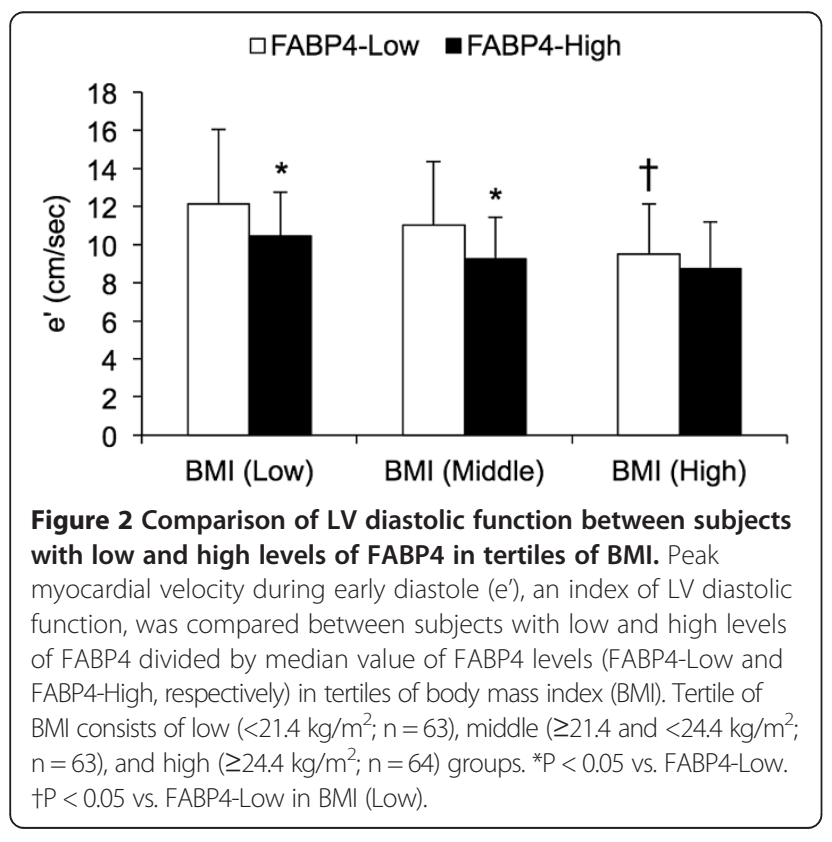

secreted from adipocytes in a non-classical secretion pathway in relation to lipolysis [9]. Although most of the recruited subjects in the present study were considered to be healthy, relatively high level of lipolytic stimuli, such as inflammatory cytokines, catecholamines and natriuretic peptides, in asymptomatic cardiac dysfunction may increase serum FABP4 concentration.

Circulating FABP4 level was associated with increased LV mass in overweight and obese women [31] and in patients with obstructive sleep apnea syndrome [32]. Recent studies also showed an independent correlation of elevated serum FABP4 with NT-proBNP in heart failure patients [33] or deterioration of LV systolic function in non-obese patients hospitalized for acutely decompensated heart failure [26] and in patients with coronary artery disease [34]. In contrast, there was no significant association between FABP4 level and concurrent [32] or subsequently developed [27] systolic dysfunction in subjects without obvious cardiac disease. In the present study using apparently healthy subjects with no medication, serum FABP4 level was weakly correlated with mean LV wall thickness but with LV mass index or LV ejection fraction. These findings suggest only a marginal 
contribution of FABP4 to development of the early phase of LV hypertrophy and systolic dysfunction.

Similar to our results, a very recent study by Baessler et al. [35] demonstrated that FABP4 level was independently correlated with e' after adjustment of age, sex and adiposity in 96 obese subjects and 24 healthy normal weight control subjects, although the association of FABP4 levels with LV diastolic dysfunction was mainly observed in obese subjects with metabolic complications but not in metabolically healthy obese subjects. However, LV diastolic dysfunction in the previous study was defined by combination of several parameters, such as e', E/e', E/A, E-wave deceleration time and left atrial dimension. This definition may affect the results. Of note, we showed that FABP4 level was an independent predictor of e', which is known as an index of LV relaxation and one of the most sensitive indicator of LV diastolic function compared with other indices, especially in a healthy population [14].

A genetic variant at the FABP4 locus associated with decreased FABP4 expression in adipose tissue has been reported to reduce the risk of cardiovascular disease in a population study [36]. We and others previously showed that serum FABP4 level predicts long-term cardiovascular events [37-39]. Furthermore, a large-scale prospective study showed that concentration of FABP4 predicted the risk of heart failure during a median follow-up of 10.7 years [27]. Accumulating evidence of a causative role of FABP4 in cardiac dysfunction would prove that FABP4 is a novel target for prevention of heart failure.

Since FABP4 is a low-molecular-weight protein and freely filtered at the glomerulus, a decrease in glomerular function was shown to result in an elevation of FABP4 concentration [37]. In the present study, FABP4 was negatively correlated with eGFR but remained as an independent predictor of LV diastolic dysfunction even after adjusting for renal function. Besides eGFR, multivariate regression analysis demonstrated that the association of FABP4 level with LV diastolic dysfunction was independent of blood pressure, LV wall thickness and BNP, a well-known predictor of cardiac damage.

The present study has some limitations. Since it has been reported that several drugs, including statin, angiotensin II receptor blocker and peroxisome proliferatoractivated receptor $\gamma$ agonist, affect FABP4 concentrations [40-42], we excluded subjects who had been treated with any drugs in the present study. Therefore, only a small number of subjects could be enrolled, and the statistical power was not large. Another limitation of this study is its cross-sectional design. Prospective longitudinal studies using larger numbers of subjects with no medication are necessary for determining whether FABP4 level is indeed a major determinant of subsequent development of cardiac dysfunction. In addition, the results of our study rely on correlation analyses. A direct relationship between
FABP4 level and progression of LV diastolic dysfunction remains unclear. This issue warrants further investigation using an interventional approach.

\section{Conclusions}

The present study is the first study to show an independent association of serum FABP4 level with LV diastolic dysfunction in a general population. The increase in serum FABP4 concentration might precede development of the early phase of cardiac dysfunction. Whether FABP4 can serve as a biomarker for early diagnosis of high-risk individuals with heart disease and a potential therapeutic target for cardiac dysfunction warrants further investigation.

\section{Competing interests}

The authors declare that they have no competing interests.

\section{Authors' contribution}

Collection and analysis of data: TF, MF, SY, AM, MK, MD, TMita, SI, YW, KH, MT, KO, HY. Draft of the manuscript: MF, TMiura. All authors read and approved the final manuscript.

\section{Acknowledgements}

MF has been supported by grants from JSPS KAKENHI, Uehara Memorial Foundation, SENSHIN Medical Research Foundation, Japan Diabetes

Foundation, Takeda Medical Research Foundation, Ono Medical Research Foundation, Takeda Science Foundation and Akiyama Life Science Foundation.

\section{Author details}

${ }^{1}$ Department of Cardiovascular, Renal and Metabolic Medicine, Sapporo Medical University School of Medicine, S-1, W-16 Chuo-ku, Sapporo 060-8543, Japan. Department of Clinical Laboratory Medicine, Chuo-ku, Sapporo 060-8543, Japan. ${ }^{3}$ Department of Public Health, Sapporo Medical University School of Medicine, Chuo-ku, Sapporo 060-8543, Japan. ${ }^{4}$ Department of Nursing, Division of Medical and Behavioral Subjects, Sapporo Medical University School of Health Sciences, Chuo-ku, Sapporo 060-8543, Japan. ${ }^{5}$ Sapporo Medical University, S-1, W-16, Chuo-ku, Sapporo 060-8543, Japan.

Received: 24 June 2014 Accepted: 8 August 2014

Published: 21 August 2014

\section{References}

1. Furuhashi M, Hotamisligil GS: Fatty acid-binding proteins: role in metabolic diseases and potential as drug targets. Nat Rev Drug Discov 2008, 7:489-503.

2. Furuhashi M, Ishimura S, Ota H, Miura T: Lipid chaperones and metabolic inflammation. Int J Inflam 2011, 2011:642612.

3. Iso T, Maeda K, Hanaoka H, Suga T, Goto K, Syamsunarno MR, Hishiki T, Nagahata Y, Matsui H, Arai M, Yamaguchi A, Abumrad NA, Sano M, Suematsu M, Endo K, Hotamisligil GS, Kurabayashi M: Capillary endothelial fatty acid binding proteins 4 and 5 play a critical role in fatty acid uptake in heart and skeletal muscle. Arterioscler Thromb Vasc Biol 2013, 33:2549-2557.

4. Hotamisligil GS, Johnson RS, Distel RJ, Ellis R, Papaioannou VE, Spiegelman BM: Uncoupling of obesity from insulin resistance through a targeted mutation in aP2, the adipocyte fatty acid binding protein. Science 1996, 274:1377-1379.

5. Makowski L, Boord JB, Maeda K, Babaev VR, Uysal KT, Morgan MA, Parker RA, Suttles J, Fazio S, Hotamisligil GS, Linton MF: Lack of macrophage fatty-acid-binding protein aP2 protects mice deficient in apolipoprotein E against atherosclerosis. Nat Med 2001, 7:699-705.

6. Furuhashi M, Fucho R, Gorgun CZ, Tuncman G, Cao H, Hotamisligil GS: Adipocyte/macrophage fatty acid-binding proteins contribute to metabolic deterioration through actions in both macrophages and adipocytes in mice. J Clin Invest 2008, 118:2640-2650. 
7. Furuhashi M, Tuncman G, Gorgun CZ, Makowski L, Atsumi G, Vaillancourt E, Kono K, Babaev VR, Fazio S, Linton MF, Sulsky R, Robl JA, Parker RA, Hotamisligil GS: Treatment of diabetes and atherosclerosis by inhibiting fatty-acid-binding protein aP2. Nature 2007, 447:959-965.

8. Xu A, Wang Y, Xu JY, Stejskal D, Tam S, Zhang J, Wat NM, Wong WK, Lam KS: Adipocyte fatty acid-binding protein is a plasma biomarker closely associated with obesity and metabolic syndrome. Clin Chem 2006, 52:405-413.

9. Cao H, Sekiya M, Ertunc ME, Burak MF, Mayers JR, White A, Inouye K, Rickey LM, Ercal BC, Furuhashi M, Tuncman G, Hotamisligil GS: Adipocyte lipid chaperone AP2 is a secreted adipokine regulating hepatic glucose production. Cell Metab 2013, 17:768-778.

10. Yeung DC, Xu A, Cheung CW, Wat NM, Yau MH, Fong CH, Chau MT, Lam KS: Serum adipocyte fatty acid-binding protein levels were independently associated with carotid atherosclerosis. Arterioscler Thromb Vasc Biol 2007, 27:1796-1802.

11. Ota H, Furuhashi M, Ishimura S, Koyama M, Okazaki Y, Mita T, Fuseya T, Yamashita T, Tanaka M, Yoshida H, Shimamoto K, Miura T: Elevation of fatty acid-binding protein 4 is predisposed by family history of hypertension and contributes to blood pressure elevation. Am J Hypertens 2012, $25: 1124-1130$

12. Ishimura S, Furuhashi M, Watanabe $Y$, Hoshina K, Fuseya T, Mita T, Okazaki $Y$, Koyama M, Tanaka M, Akasaka H, Ohnishi H, Yoshida H, Saitoh S, Miura T: Circulating levels of fatty acid-binding protein family and metabolic phenotype in the general population. PLOS One 2013, 8:e81318.

13. Ouwens DM, Sell H, Greulich S, Eckel J: The role of epicardial and perivascular adipose tissue in the pathophysiology of cardiovascular disease. J Cell Mol Med 2010, 14:2223-2234.

14. Lang RM, Bierig M, Devereux RB, Flachskampf FA, Foster E, Pellikka PA, Picard MH, Roman MJ, Seward J, Shanewise JS, Solomon SD, Spencer KT Sutton MS, Stewart WJ: Recommendations for chamber quantification: a report from the American Society of Echocardiography's Guidelines and Standards Committee and the Chamber Quantification Writing Group, developed in conjunction with the European Association of Echocardiography, a branch of the European Society of Cardiology. J Am Soc Echocardiogr 2005, 18:1440-1463.

15. Roger VL: Epidemiology of heart failure. Circ Res 2013, 113:646-659.

16. Ho JE, Lyass A, Lee DS, Vasan RS, Kannel WB, Larson MG, Levy D: Predictors of new-onset heart failure: differences in preserved versus reduced ejection fraction. Circ Heart Fail 2013, 6:279-286.

17. Sacks HS, Fain JN: Human epicardial adipose tissue: a review. Am Heart $J$ 2007, 153:907-917.

18. Ichikawa R, Daimon M, Miyazaki T, Kawata T, Miyazaki S, Maruyama M, Chiang SJ, Suzuki H, Ito C, Sato F, Watada H, Daida H: Influencing factors on cardiac structure and function beyond glycemic control in patients with type 2 diabetes mellitus. Cardiovasc Diabetol 2013, 12:38.

19. Vural B, Atalar F, Ciftci C, Demirkan A, Susleyici-Duman B, Gunay D, Akpinar B, Sagbas E, Ozbek U, Buyukdevrim AS: Presence of fatty-acid-binding protein 4 expression in human epicardial adipose tissue in metabolic syndrome. Cardiovasc Pathol 2008, 17:392-398.

20. Lamounier-Zepter V, Look C, Alvarez J, Christ T, Ravens U, Schunck WH, Ehrhart-Bornstein M, Bornstein SR, Morano I: Adipocyte fatty acid-binding protein suppresses cardiomyocyte contraction: a new link between obesity and heart disease. Circ Res 2009, 105:326-334.

21. Aragones G, Saavedra P, Heras M, Cabre A, Girona J, Masana L: Fatty acid-binding protein 4 impairs the insulin-dependent nitric oxide pathway in vascular endothelial cells. Cardiovasc Diabetol 2012, 11:72.

22. Tanaka T, Hirota Y, Sohmiya K, Nishimura S, Kawamura K: Serum and urinary human heart fatty acid-binding protein in acute myocardial infarction. Clin Biochem 1991, 24:195-201.

23. Setsuta K, Seino Y, Ogawa T, Arao M, Miyatake Y, Takano T: Use of cytosolic and myofibril markers in the detection of ongoing myocardial damage in patients with chronic heart failure. Am J Med 2002, 113:717-722.

24. Anker SD, von Haehling S: Inflammatory mediators in chronic heart failure: an overview. Heart 2004, 90:464-470.

25. Vasan RS, Sullivan LM, Roubenoff R, Dinarello CA, Harris T, Benjamin EJ, Sawyer DB, Levy D, Wilson PW, D'Agostino RB: Inflammatory markers and risk of heart failure in elderly subjects without prior myocardial infarction: the Framingham Heart Study. Circulation 2003, 107:1486-1491.

26. Liu M, Zhou M, Bao Y, Xu Z, Li H, Zhang H, Zhu W, Zhang J, Xu A, Wei M, Jia W: Circulating adipocyte fatty acid-binding protein levels are independently associated with heart failure. Clin Sci 2013, 124:115-122
27. Djousse L, Bartz TM, Ix JH, Kochar J, Kizer JR, Gottdiener JS, Tracy RP, Mozaffarian D, Siscovick DS, Mukamal KJ, Zieman SJ: Fatty acid-binding protein 4 and incident heart failure: the Cardiovascular Health Study. Eur J Heart Fail 2013, 15:394-399.

28. Levine B, Kalman J, Mayer L, Fillit HM, Packer M: Elevated circulating levels of tumor necrosis factor in severe chronic heart failure. $N$ Engl J Med 1990, 323:236-241.

29. von Haehling S, Lainscak M, Springer J, Anker SD: Cardiac cachexia: a systematic overview. Pharmacol Ther 2009, 121:227-252.

30. Scheja L, Makowski L, Uysal KT, Wiesbrock SM, Shimshek DR, Meyers DS, Morgan M, Parker RA, Hotamisligil GS: Altered insulin secretion associated with reduced lipolytic efficiency in aP2-/- mice. Diabetes 1999, 48:1987-1994.

31. Engeli S, Utz W, Haufe S, Lamounier-Zepter V, Pofahl M, Traber J, Janke J, Luft FC, Boschmann M, Schulz-Menger J, Jordan J: Fatty acid binding protein 4 predicts left ventricular mass and longitudinal function in overweight and obese women. Heart 2013, 99:944-948.

32. Balci MM, Arslan U, Firat H, Kocaoglu I, Vural MG, Balci KG, Maden O, Gurbuz $\mathrm{OA}$, Ardic S, Yeter E: Serum levels of adipocyte fatty acid-binding protein are independently associated with left ventricular mass and myocardial performance index in obstructive sleep apnea syndrome. J Investig Med 2012, 60:1020-1026.

33. Cabre A, Valdovinos P, Lazaro I, Bonet G, Bardaji A, Masana L: Parallel evolution of circulating FABP4 and NT-proBNP in heart failure patients. Cardiovasc Diabetol 2013, 12:72

34. Huang CL, Wu YW, Wu CC, Lin L, Wu YC, Hsu PY, Jong YS, Yang WS: Association between serum adipocyte fatty-acid binding protein concentrations, left ventricular function and myocardial perfusion abnormalities in patients with coronary artery disease. Cardiovasc Diabetol 2013, 12:105.

35. Baessler A, Lamounier-Zepter V, Fenk S, Strack C, Lahmann C, Loew T, Schmitz G, Bluher M, Bornstein SR, Fischer M: Adipocyte fatty acid-binding protein levels are associated with left ventricular diastolic dysfunction in morbidly obese subjects. Nutr Diabetes 2014, 4:e106.

36. Tuncman G, Hirosumi J, Solinas G, Chang L, Karin M, Hotamisligil GS: Functional in vivo interactions between JNK1 and JNK2 isoforms in obesity and insulin resistance. Proc Natl Acad Sci U S A 2006, 103:10741-10746.

37. Furuhashi M, Ishimura S, Ota H, Hayashi M, Nishitani T, Tanaka M, Yoshida H, Shimamoto K, Hotamisligil GS, Miura T: Serum fatty acid-binding protein 4 is a predictor of cardiovascular events in end-stage renal disease. PLOS One 2011, 6:e27356

38. von Eynatten M, Breitling LP, Roos M, Baumann M, Rothenbacher D, Brenner $\mathrm{H}$ : Circulating adipocyte fatty acid-binding protein levels and cardiovascular morbidity and mortality in patients with coronary heart disease: a 10-year prospective study. Arterioscler Thromb Vasc Biol 2012, 32:2327-2335.

39. Chow WS, Tso AW, Xu A, Yuen MM, Fong CH, Lam TH, Lo SV, Tse HF, Woo YC, Yeung CY, Cheung BM, Lam KS: Elevated circulating adipocyte-fatty acid binding protein levels predict incident cardiovascular events in a community-based cohort: a 12-year prospective study. J Am Heart AssoC 2013, 2:e004176.

40. Karpisek M, Stejskal D, Kotolova H, Kollar P, Janoutova G, Ochmanova R, Cizek L, Horakova D, Yahia RB, Lichnovska R, Janout V: Treatment with atorvastatin reduces serum adipocyte-fatty acid binding protein value in patients with hyperlipidaemia. Eur J Clin Invest 2007, 37:637-642.

41. Miyoshi T, Doi M, Hirohata S, Kamikawa S, Usui S, Ogawa H, Sakane K, Izumi $R$, Ninomiya $Y$, Kusachi S: Olmesartan reduces arterial stiffness and serum adipocyte fatty acid-binding protein in hypertensive patients. Heart Vessels 2011, 26:408-413.

42. Cabre A, Lazaro I, Girona J, Manzanares JM, Marimon F, Plana N, Heras M Masana L: Fatty acid binding protein 4 is increased in metabolic syndrome and with thiazolidinedione treatment in diabetic patients. Atherosclerosis 2007, 195:e150-158.

doi:10.1186/s12933-014-0126-7

Cite this article as: Fuseya et al:: Elevation of circulating fatty acid-binding protein 4 is independently associated with left ventricular diastolic dysfunction in a general population. Cardiovascular Diabetology 2014 13:126. 